\title{
Learning from listening: Introduction of Community Based Participatory Research methods to medical students
}

\author{
Selvaraj, K. ${ }^{1}$, Ramalingam, A. $^{2}$, Kar, S.S. ${ }^{4}$
}

\begin{abstract}
Background: Qualitative research methods are unpopular among medical graduates. Quantitative surveys followed by exploring issues with the community by participatory research methods will facilitate health providers in educating the community against any misconceptions that exist in the community related to illnesses.

Methods: Third-year medical graduates were taught regarding participatory research in their community diagnosis training. With a prior introduction, supervision and guidance under faculty members, students carried out a body mapping exercise among villagers of Katrambakkam in the state of Tamil Nadu, India. Female groups which consisted of seven people had drawn body map along with symptoms in the sequence of commonality and severity of symptoms.

Results: The body map drawn for diabetes mellitus and hypertension showed that among these villagers, knowledge and understanding towards diabetes was higher when compared to hypertension. Training of medical graduates in these kinds of participatory exercises will help in providing contextspecific interventions in the community.
\end{abstract}

Key words: Body map, Community based participatory research, knowledge, medical graduates, Noncommunicable diseases, Rural

\section{Introduction}

With globalization and urbanization disease patterns have undergone a change and Non Communicable diseases (NCDs) are on the rise globally. By their nature of symptomless onset of disease and lack of perceived threat, noncommunicable diseases are prone to late detection and poor compliance.

\footnotetext{
${ }^{1}$ Senior Resident

2 Junior Resident

${ }^{3}$ Associate Professor

Department of Preventive and Social Medicine, Jawaharlal Institute of Postgraduate Medical Education and Research (JIPMER), Puducherry, India

Corresponding Author:

Dr. Sitanshu Sekhar Kar

Associate Professor

Department of Preventive and Social Medicine

Jawaharlal Institute of Postgraduate Medical Education and

Research (JIPMER)

Puducherry, India.
}

Email:drsitanshukar@gmail.com
Health education remains an important tool to emphasize the importance of lifestyle modifications to members of the community. To plan a successful health education campaign, it is vital to explore the understanding of community members regarding NCDs and the social context surrounding these diseases so that appropriate sessions can be planned.

Qualitative studies differ from their quantitative counterparts in that they offer an insight into the perceptions of the participants regarding the diseases or risk factors studied, whereas quantitative studies knowingly or unknowingly limit their boundaries to the variables in the questionnaire framed from previous literature or experience.

Community-Based Participatory Research (CBPR) methods are well known as they augment the understanding of the social context in which the particular disease or risk factor is being studied. CBPR is defined as "systematic inquiry, with the participation of those affected by the issue being studied, for the purposes of education and taking action or 
affecting social change" (Leung et al., 2004). There are various methods of participatory research (timeline, calendar, Venn diagram, body mapping etc) described in the literature. Of all these methods, mapping techniques are perhaps the simplest ones and they actively involve the community (Mukherjee, 2002; Tolley et al., 1992).

Body maps are health data gathering tools that illustrate parts of the human body. Verbal communications alone may not be able to explain how the community perceives various bodily functions and healthcare interventions. (Archer, 1996). A body map exercise carried out among dais of the South African region has demonstrated how real perceptions are different from interviewer's assumptions about the participant knowledge in terms of reproductive tract and process of delivery. The body mapping exercise seals the gap between biological knowledge and people's perception. Knowing the people's knowledge about their own body will facilitate counselling process for health care providers thereby the compliance towards health care measures.

Since these CBPR techniques will be helpful for medical graduates, who would be future medical officers and program managers, a CBPR session was planned as a part of the community diagnosis posting to explore the understanding of community members regarding Diabetes and Hypertension in a rural area of Tamil Nadu.

\section{Methods}

This body mapping exercise was carried out in a village of Tamil Nadu named Katrambakkam, which is located $15 \mathrm{~km}$ away from the hospital affiliated with the Jawaharlal Institute of Postgraduate Medical Education and Research (JIPMER).

Community Diagnosis posting: As part of the Preventive and Social Medicine teaching curriculum students are given field experience through three community diagnosis postings over seven semesters. The main aim of the community diagnosis posting is to make the students understand the prevalent diseases, treatment- seeking behaviour, people's awareness the diseases and their prevention measures. After prior liaison work by the department, students are taken to nearby villages for community orientation. Each community diagnosis (CD) posting lasts for 30 days, initial three weeks of a survey with a prestructured questionnaire and one week on community- based participatory research techniques and intervention by health education. This exercise was planned to make the students understand the purpose of mapping and enable them to carry out various mapping techniques on their own.

Setting: Katrambakkam has a total population of around 3500. Agriculture and work under the Mahathma Gandhi National Rural Employment Guarantee were the major occupations of the people in this village. Majority of them belong to lower middle socioeconomic class. Scheduled caste and vanniyar (Most Backward Class) are predominant castes seen in this village. People often use community hall or drama stage for public gatherings.

\section{Preparation}

We followed the concept of body mapping based on principles of Cornwall et al. (Tolley, 1992; Cornwall et al., 1995; Cornwall, 1992) Third-year medical graduates were briefed on this technique by faculty and then they were introduced to the community members to carry out this exercise. A prior community mobilization was done through house to house visits by the students. With all the necessary materials, students and community members gathered near the drama stage. Since some of the shared information in body map could be sensitive two separate teams were formed for males and females respectively. The body map drawn by the female group is discussed in this paper.

\section{Body mapping exercise}

In this exercise, students used body mapping to focus on the understanding of the community towards the effects of Diabetes and Hypertension on various organs (figure 1). The female group had seven participants of whom one had completed high school, two had completed primary education and four were illiterate. None of the participants had a history of diabetes or hypertension. However, three of the participants had at least one family member (in-laws, spouse etc.) who suffered from one of these diseases. 


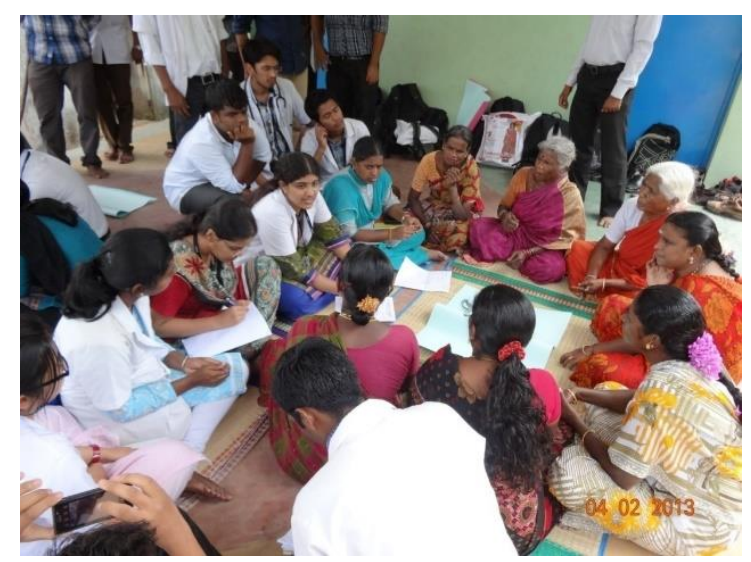

Figure 1: Medical students meeting with community members for body mapping exercise

Before the activity, instructions were given by the postgraduate students of Community Medicine. Community members were requested to draw the body map based on their perception about the effect of the diseases (in terms of symptoms and complications-in order of frequency and of perceived severity). After every member of the group had given their opinion a consensus was drawn by the group. This body mapping activity took 30 minutes to complete. The body map drawn by the community is shown in figure 2 .

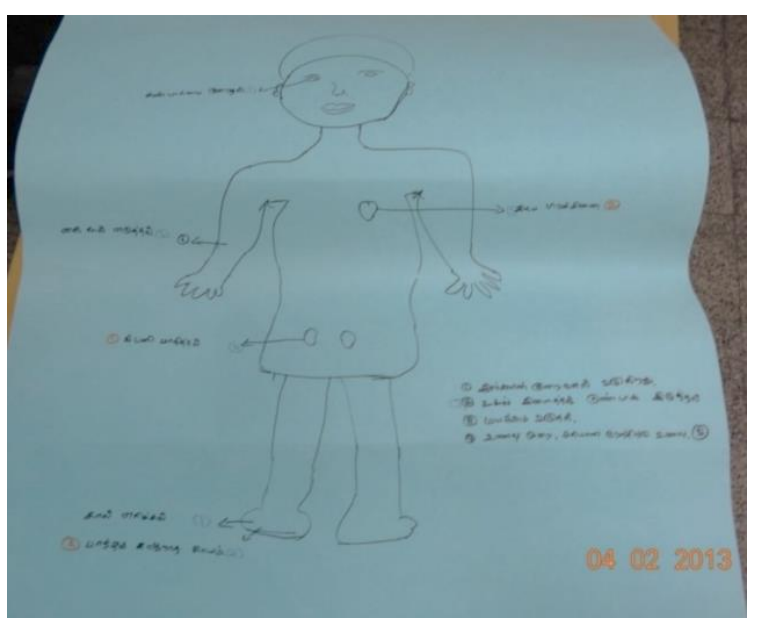

Figure 2: List of symptoms drawn by body mapping exercise for Diabetes

\section{Results}

The list of symptoms drawn by community members (Figure 2) in order of frequency were:
1. "burning of foot"
2. $\quad$ "non-healing ulcer in foot"
$3 . \quad$ "decrease in vision"
$4 . \quad$ "kidney damage"
5. $\quad$ "heart problems"
6. "removal of hand and feet"
7. $\quad$ "loss of weight or being obese"
8. "fainting"
9. "food method, meals at appropriate time

Upon probing the group felt that diabetic patients had to take meals at an appropriate time. This they attribute to nature of illness due to "substance synthesized" from the stomach region. They attributed complaints like burning feet, kidney damage, heart problems and fainting to nerve damage.

The complications in order of severity were represented in a different colour (Figure 2). The group had marked kidney damage as the most severe complication.

The list of responses for "complications of Diabetes" from most severe to least severe was: (Figure 2)
1. "kidney damage"
2. "heart problems"
3. "non-healing ulcer in foot"

When the same process was asked to be drawn for hypertension the group had drawn the body outline alone and reported that they only knew that fainting was a symptom of hypertension (Figure 3).

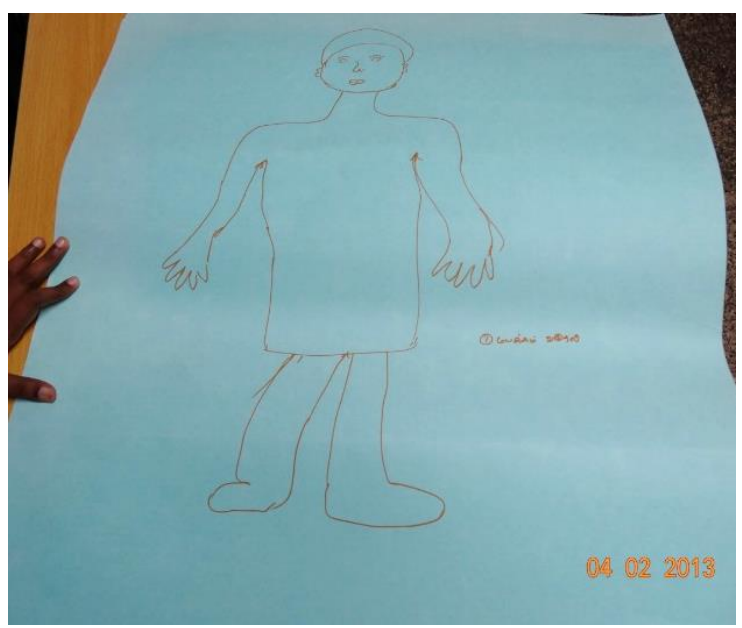

Figure 3: List of symptoms drawn by body mapping exercise for hypertension 


\section{Discussion}

The exercise was conducted in a place accessible to all the members of the village (drama stage). Thus, participation from various sections of the community was facilitated. Since a participatory method was followed, the perception of the women in the village about symptoms and complications of diabetes and hypertension could be captured accurately.

The women participated in the exercise enthusiastically and the medical students paid rapt attention to the whole process. The body mapping exercise was completed in 30 minutes. The body maps drawn by the women illustrate their understanding of the common symptoms and complications of diabetes and hypertension. The women had demonstrated that they knew a lot about diabetes, but not so much in the case of hypertension. This may be because of many focused IEC (information, communication and education) activities that are related to diabetes.

This exercise made the students understand that the women in Kattrampakkam had a lot of knowledge gap about hypertension. Hence, they planned a health education session to focus on hypertension.

\section{Lessons learnt}

The exercise provided an opportunity for students to observe the importance of understanding the knowledge and perceptions of community members in planning health education sessions related to NCDs. At the end of this process feedback from students was obtained. Students were of the opinion that since they were actively communicating with group members every moment, they could enjoy the process throughout and they would like to replicate this same process in future too. Additionally, students have replied that this process helps in understanding the misconception of the community towards illnesses. The exercise would make them realize that health education should be designed based on the knowledge gaps and felt needs of the community. In this way, the messages delivered would be more acceptable to the population. Since the women in Kattrampakkam had a lot of knowledge gap about hypertension the students planned a health education session to focus on hypertension.

The Medical Council of India strongly emphasizes on producing a culturally competent physician. Interactive education methods beyond the classroom boundaries and teaching practical skills instead of theoretical frameworks would help in moulding the students based on the needs of the present day practice of medicine.

\section{Conflicts of interest: None}

\section{References}

Archer, D. \& Cottingham, S. (1996) Action Research Report on REFLECT--Regenerated Freirean Literacy through Empowering Community Techniques, The Experiences of Three REFLECT Pilot Projects in Uganda, Bangladesh, El Salvador. Serial No. 17, Reflect Mother Manual. London: ActionAid.

Cornwall, A. (1992) Body mapping in health RRA/PRA, RRA Notes, 16, pp 69-76.

Cornwall, A. \& Jewkes, R. (1995) What is participatory research? Social Science \& Medicine, 41, 12, pp. 1667-1676.

Leung, M.W., Yen, I.H. \& Minkler, M. (2004) Community based participatory research: a promising approach for increasing epidemiology's relevance in the 21st century, International Journal of Epidemiology, 33, 3, pp. 499-506.

Mukherjee, N. (2002) Participatory learning and action: With 100 field methods [Internet]. Concept Publishing Company [cited 2013 Aug 25]. Available from: http://books.google.co.in/ books? $h l=e n \& l r=\& i d=C P D y / Q 5 \_R K A C \& o i=f n d$ $\& p g=P A 7 \& d q=$ neela + mukerjee+field + methods \&ots=r4FXYpgmZq\&sig=rc_pr2usHIV2kU3RG5 pKn835WA.

Tolley, E. \& Bentley, M.E. (1992) Participatory methods for research on women's reproductive health. International Institute for Environment and Development, 16, pp. 63-68. 